\title{
An Emerging Course Topic: The Regulation of Pharmaceuticals and Medical Devices
}

\author{
Christine Kelly \\ Department of Chemical Engineering, Oregon State University
}

Introduction

This paper describes a new course in the area of the regulatory environment for pharmaceutical products and medical devices. The course was offered for the first time in the fall of 2004 as a required course in the undergraduate Bioengineering Program housed within the Chemical Engineering Department at Oregon State University (OSU). The course was a ten week quarter system course worth three credits.

\section{Motivation}

The motivation for development of this course was regulated industry employers' criticism that new engineers are uninformed of the regulatory driving forces that influence engineering practice in their companies. Young engineers spend a significant amount of time learning regulatory issues at expense to the company and detriment to their learning curve for the new position. The course was developed by faculty and a pharmaceutical company employee who worked in the areas of validation and quality control.

\section{Learning Objectives}

Five course learning objectives were provided to the students at the beginning of the fall 2004 term, and two will be added for the next offering. These seven learning objectives are indicated in Table 1.

\section{Course Content}

The course provided an overview of work in a regulated environment, using a biopharmaceutical manufacturing facility as the example environment. Figure 1 illustrates the topics presented in the course. The seven major topics include (1) the drug and medical device approval process, (2) current good manufacturing practices, (3) biopharmaceutical processing overview, (4) process documentation (primarily standard operating procedures and batch records), (5) validation, (6) quality assurance, quality control and analytical methods, and (7) control strategies. Required readings supplemented the lecture material and are indicated in Table 2. 
Table 1. Course learning objectives

By the end of the course, students must demonstrate ability to...

1. In writing, explain the drug and medical device approval process in the United States. The explanation should include a description of the structure of the regulatory agency, important regulatory documents, the sequence of events, applications necessary, and the players involved.

2. Define, obtain the regulatory codes, and describe the FDA's guidance strategy for Current Good Manufacturing Practices (cGMP).

3. Draw a process flow diagram for a variety of biopharmaceutical manufacturing process and describe the operation and purpose of each unit, including water systems.

4. Develop regulatory documentation (standard operating procedure and batch record) for a given process.

5. Develop and critique a peer's written validation plan for a given process and carry out the plan in the laboratory. Synthesize the results into a final validation document.

6. Define the roles and describe the differences between Quality Assurance and Quality Control groups. Select analytical methods and quality tools appropriate for quality control of a biopharmaceutical process or medical devices manufacturing process and explain the fundamental basis for the methods.

7. Describe the purpose and components control strategies, including change control systems, process deviations, and quality investigations.

Table 2. Required readings

Parts of the U.S. Food and Drug Administrations web site

Example batch records

Example standard operating procedures

Example validation documents

Sections of the United States Pharmacopoeia: National Formulary (USP24:NF19). The Official compendia of Standards.

Hardy, Mark R. Methods for the analysis of glycoprotein carbohydrates. Available at the URL http://www.abrf.org/ABRFNews/1994/April1994/apr94methods.html.

Huber, Ludwig. 2003. Validation of analytical methods and processes. In

Pharmaceutical Process Validation edited by Robert A. Nash and Alfred H. Wachter.

Pages 507-524. Marcel Dekker, Inc.

Lincoln, John E. The FDA's draft process validation guidance. Journal of Validation

Technology. 5(3):263-270.

Reisman, Harold B. Eight rules to live by for successful validations. Journal of Validation Technology. 1(4):56-59

U.S. FDA. 1991. Biotechnology Inspection Guide Reference Materials and Training Aids. Available at the URL http://www.fda.gov/ora/inspect_ref/igs/biotech.html.

Waterland, Nellie; Shapiro, Matthew; Douty, Charles; Grice-DuBose, ArDen; McKinley, Sophia; Thrasher, Gerri; and Ulmer, Marissa. Change Control: Seven Pharmaceutical manufacturers Share Their Experiences. Available at the URL

http://www.ivthome.com/free/change $\% 20$ control.htm.

"Proceedings of the 2005 American Society for Engineering Education Annual Conference \& Exposition Copyright (C) 2005, American Society for Engineering Education", 
1. Drug and Medical Device Approval Process

- Overview and history of the FDA, and FDA centers

- Pre-clinical drug development

- Investigation new drug application (IND): purpose and contents

- Clinical trials

- New drug application (NDA): purpose and contents

- Preapporaval inspection

- FDA post marketing programs

2. Current Good Manufacturing Practices (cGMPs)

- Definition and description of current good manufacturing practices

- Federal Register

- Code of Federal Regulations

- cGMP enforcement (FDA 483 forms, recalls, warning letters, license suspension, seizures, consent decree, criminal prosecution)

3. Example process for course content applications

- Biopharmaceutical manufacturing (cell banking, fermentation and cell culture, ultrafiltration and chromatography, pharmaceutical water and water for injection, decontamination and sanitation of process equipment, final product formulation)

- Contract manufacturing

4. Documentation (Standard Operating Procedures and Batch Records)

- Definition and regulatory justification of Standard Operating Procedures

- Example SOPs

- Process documentation requirements: batch records definition and description

- Example batch records

5. Validation

- Definition of validation

- The six validations (analytical method, computer systems, utilities, cleaning, process and training)

- Process validation format (Installation Qualification, Operation Qualification, Performance Qualification)

- Example validation protocols and reports

- Prospective/retrospective validation

- Analytical method validation

- Medical device validation

- Quality tools (SPC)

6. QA/QC and Analytical Methods

- QA and QC definition and differences

- Unites States Pharmacopoeia and National Formulary

- Performance characteristics (accuracy, precision, specificity, reproducibility, etc.)

- Relevant analytical methods (bioburden, protein analyses, stability, endotoxin determination, titer [HPLC], glycoproteins)

7. Control Strategies

- Change control

- Deviations and investigations

Figure 1. Regulation of drugs and medical devise course content outline

"Proceedings of the 2005 American Society for Engineering Education Annual Conference \& Exposition Copyright (C) 2005, American Society for Engineering Education"” 
The course began with discussions about the drug and medical device approval process in the U.S. Much of the content for this section of the course is derived from the FDA website, supplemented from articles from the literature. The students participated in role playing the approval process with groups of students acting as (1) research and development scientists, (2) toxicologists, (3) quality assurance and quality control personnel, (4) management, (5) development and process engineers, (6) manufacturing personnel, (7) clinicians, (8) clinical trial industrial review board members, (9) clinical trial participants, and (10) FDA regulators. The students wrote a brief paper on the approval process for drugs and for medical devices.

The concept of cGMPs was introduced through a discussion of the Federal Register and Code of Federal Regulations. Groups of students were provided an actual warning letter with reference to deficiencies in cGMP. The students were required to present to their peers the major issues in the warning letter and retrieve the section of the Code of Federal Regulations that applied. The nature of expectations of the FDA communicated through published warning letters was emphasized.

An example process of mammalian cell monoclonal antibody biosynthesis was used for reference in discussing course material. This process was briefly discussed with particular emphasis on pharmaceutical water and water for injection.

The students used the cell culture part of this example process to develop their own standard operating procedures and batch records. Example SOPs and batch records from industry were reviewed prior to the students' efforts.

One of the major topics in the course was process and analytical method validation. The students prepared simple validation plans and performed experiments for the validation of measuring $\mathrm{pH}$ and determining the color of a sample to introduce the validation concept. Subsequently, the students performed a theoretical validation on the monoclonal antibody cell culture process and produced a final validation document containing the Installation Qualification, Operation Qualification, and Performance Qualification sections. A rough draft of the document was prepared, followed by peer and instructor critiques, and then a final draft was submitted.

The roles of Quality Assurance and Quality Control were discussed in relation to the processing environment. Analytical methods relevant to pharmaceutical processing and medical device manufacture were introduced. Emphasis was placed on the role of the Unites States Pharmacopeia and National Formulary as the compendium reference for appropriate analytical methods. Material on change control systems, process deviations, and quality investigations completed the topics covered in the course.

\section{Student Learning Assessments and Evaluation}

Student learning was assessed through multiple measures for each learning objective. Assessment included homework, presentations, quizzes, and a comprehensive final exam. The types of assessments used are indicated in Table 3. 
Table 3. Types of assessments

\begin{tabular}{l}
\hline \hline Drug approval process role play. \\
\hline Written paper describing the drug and medical device approval process. \\
\hline $\begin{array}{l}\text { Short Power point presentations to the class on an actual FDA warning letter. The } \\
\text { presentations required the inclusion of applicable sections of the Code of Federal } \\
\text { Regulations. }\end{array}$ \\
\hline $\begin{array}{l}\text { Qualitative and quantitative homework assignments based on readings and lectures. The } \\
\text { assignments included topics of statistical process control, analytical methods, change } \\
\text { control and process deviations. }\end{array}$ \\
\hline Development of an SOP for the example process and a critique of peer's SOP. \\
\hline Development of a batch record for the example process. \\
\hline $\begin{array}{l}\text { Development and performance of a validation protocol for a simple analytical method, } \\
\text { synthesis into a final validation document, and critique of peer's validation document. }\end{array}$ \\
\hline $\begin{array}{l}\text { Development of a process validation document for the example process using theoretical } \\
\text { experimental data and a critique of a student peer's validation document. }\end{array}$ \\
\hline $\begin{array}{l}\text { Five quizzes. The quizzes included the topics of cGMP, process validation, analytical } \\
\text { method validation, glycolprotein analysis, and change control. }\end{array}$ \\
\hline Comprehensive final exam.
\end{tabular}

Student Evaluation

The undergraduate Bioengineering program at OSU is relatively new. Twelve students graduated from the program in 2003, eleven students in 2004, and fifteen fourth year Bioengineering students completed this course during the fall 2004 term. Fall 2004 was the first time this course was included in the curriculum. Graduating students in 2003 and 2004 and students who took this course in fall 2004 rated themselves on their competency in program outcome p, which states "the graduates of the OSU Bioengineering Program must demonstrate that they have general knowledge of regulatory issues, including pre-clinical and clinical protocols, proper documentation, and good manufacturing practices". The students' self rating was on a scale of one to six, where one represented "not competent", and six represented "completely competent". Graduating students in 2003 and 2004 gave an average self rating of 4.1 and 4.3, respectively. Many of these students referred to discussions of clinical protocols in their ethics course as evidence for their competency, perhaps not realizing the extent of regulatory issues of importance. The first cohort of students to take this course rated their competency in program outcome $\mathrm{p}$ with an average of 4.8 , a significant increase over the previous two years.

Private Sector Evaluation

The course content (Figure 1) was provided to Walter S. Pebley, Vice President, Business \& Technical Development, at Oregon Freeze Dry, Inc., an FDA registered manufacturing site with experience in lyophilizing chemicals, biotechnology products, medical devices, pharmaceuticals, and nutraceuticals. In response, Mr. Pebley stated "You have hit the nail on the head" concerning the topics presented in the course. "I have long been an advocate of inclusion of the contents you have proposed." 
Future Improvements

Mr. Pebley or Oregon Freeze Dry, Inc. suggested several improvements in the course content, including possible internships and other industry participation, such as guest lecturers. In addition, he recommended inviting FDA representatives to speak with the students to provide an additional perspective. Mr. Pebley specifically suggested including discussions on Out-OfSpecification (OOS) from analytical results during investigations of deviations and Corrective Action Plans that are derived from these investigations. In subsequent courses a more significant laboratory component will be included allowing the students to prepare standard operating procedures, batch records and validations using bench scale equipment. Students that have participated in the course will be contacted after time in the work force and asked for suggestions on improving the course.

We believe the providing students with knowledge of regulatory issues is an important aspect of their training to become work ready engineering and that this course will evolve into a successful mechanisms to impart this knowledge.

Bibliography

1. Adams, V., Askenazi, A, Building Better Products with Finite Element Analysis, Onward Press, 1999.

2. Mortenson, Michael, Mathematics for Computer Graphics, Industrial Press, 1999.

3. Mortenson, Michael, Geometric Modeling, Wiley, 1985

4. Lee, Kunwoo, Principles of CAD/CAM/CAE Systems, Prentice Hall (was Addison Wesley), 1999

5. Rogers, David F., An Introduction to NURBS: with Historical Perspective, Morgan Kaufman, 2000.

6. Rogers, David F., Adams, J. A., Mathematical Elements for Computer Graphics, McGraw-Hill, 1990

7. Zeid, Ibrahim, CAD/CAM Theory and Practice, McGraw-Hill, 1991

Bibliographic Information

1. United States Pharmacopoeia: National Formulary (USP24:NF19).

2. Hardy, Mark R. 1994. Methods for the analysis of glycoprotein carbohydrates. Association of Biomolecular Resource Facility News. April 1994.

3. Huber, Ludwig. 2003. Validation of analytical methods and processes. In Pharmaceutical Process Validation edited by Robert A. Nash and Alfred H. Wachter. Pages 507-524. Marcel Dekker, Inc.

4. Lincoln, John E. The FDA's draft process validation guidance. Journal of Validation Technology. 5(3):263270 .

5. Reisman, Harold B. Eight rules to live by for successful validations. Journal of Validation Technology. 1(4):5659

6. U.S. FDA. 1991. Biotechnology Inspection Guide Reference Materials and Training Aids. Division of Field Investigations.

7. Waterland, Nellie; Shapiro, Matthew; Douty, Charles; Grice-DuBose, ArDen; McKinley, Sophia; Thrasher, Gerri; and Ulmer, Marissa. Change Control: Seven Pharmaceutical manufacturers Share Their Experiences. Journal of GXP Compliance.

Biographical Information

CHRISTINE KELLY

"Proceedings of the 2005 American Society for Engineering Education Annual Conference \& Exposition Copyright $\left({ }^{\circ} 2005\right.$, American Society for Engineering Education" 
Christine Kelly is an Associate Professor in the Chemical Engineering Department at Oregon State University. She teaches course for the undergraduate Bioengineering Program at OSU. Prior to this she was an Assistant Professor at Syracuse University and taught Chemical Engineering courses for six years. 